\title{
EDITORIAL
}

\section{VALOR E PROJETOS: A CONTRIBUIÇÃO DA PERSPECTIVA DE MARKETING}

\author{
Flávio Santino Bizarrias \\ Universidade Nove de Julho (UNINOVE) \\ flavioxsp@hotmail.com \\ Renato Penha \\ Universidade Nove de Julho (UNINOVE) \\ rp.renatopenha@gmail.com \\ Luciano Ferreira da Silva \\ Universidade Nove de Julho (UNINOVE) \\ Doutorado em Administração na Pontifícia Universidade Católica (PUC-SP) \\ lf_silvabr@yahoo.com.br
}

\begin{abstract}
Cite como
American Psychological Association (APA)

Bizarrias, F. S., Penha, R., \& Silva, L. F. (2021, maio/ago.). Valor e projetos: a contribuição da perspectiva de marketing. Editorial. Revista de Gestão e Projetos (GeP), 12(2), 1-8. https://doi.org/10.5585/gep.v12i2.20121.
\end{abstract}

A gestão de projetos vem passando por profundas transformações ao longo dos últimos anos. Dentre estas mudanças, tem se observado uma maior permeabilidade a outras áreas do conhecimento. Isto é bastante saudável na medida em que permite que novas ou complementares abordagens em gestão de projetos possam ser incorporadas aos métodos tradicionais, ampliando assim as possibilidades de resultado de um projeto. Neste contexto, a tradicional visão de que os projetos devem ter preocupação com escopo, custo e prazo não parece responder completamente aos desafios atuais das organizações. A perspectiva tradicional vem sendo cada vez mais influenciada pelo aumento de práticas calcadas no valor gerado pelo projeto para o cliente.

Neste contexto, praticantes e estudiosos sobre gestão de projetos vêm sendo desafiados a refletir sobre uma visão baseada nas técnicas e frameworks tradicionais, e aquelas técnicas e frameworks voltados ao foco do profissional de projetos na perspectiva do cliente. Um aspecto importante nesta discussão é a relevância de tratar da perspectiva de valor percebido pelo cliente do projeto. Esta visão pode ser evidenciada pela abordagem ágil materializada em práticas presentes no framework Scrum, 
Kanban, Lean Inception, entre outras, que se diferenciam da abordagem preditiva de gestão de projetos em relação ao tempo para entregar valor para o cliente. Assim, o cliente, muitas vezes distante durante o processo de gestão de projetos que adotam uma perspectiva preditiva, passa a determinar o que é relevante e valorizado durante a gestão de seu projeto, em uma perspectiva iterativa e colaborativa.

Em suma, o desafio de entregar valor de forma iterativa consiste em adaptar as práticas gerencias orientadas ao planejamento, fortemente sustentadas pelo escopo fixo e prazo, para uma visão orientada ao valor do negócio do cliente, onde o escopo é estimado em ciclo de iterações.

Então, há uma tendência para a

proposta de valor em projetos na perspectiva do cliente. A proposta de valor entregue ao cliente de projetos a cada iteração, e não ao final do projeto. As iterações estarão centradas na experiência do cliente, não em uma entrega única e final. Esta mudança tem sido observada como ideal para projetos inseridos neste contexto de negócios cada vez mais dinâmico. Isto se deve também muito em função da crescente incerteza que demanda por respostas mais rápidas das organizações, das amplas mudanças nos seus ambientes internos e na transformação digital.

Nesta nova perspectiva, conceitos relacionados ao valor na visão do cliente emergem de maneira a representar uma orientação que parece estar cada vez mais presente nas organizações. A "jornada do cliente", a "experiência do cliente" de projetos, os aspectos "comportamentais" na gestão de projetos, a "co-criação de valor", o "Discovery" e o "Delivery" do que traz valor ao projeto, o "foco na solução evolucionária do produto" e não no projeto, são sinais de uma mudança profundas na gestão de projetos.

Com base no que foi supracitado, este editorial convida pesquisadores e praticantes de gestão de projetos a refletir sobre as mudanças na abordagem e gestão de projetos. A mudança aqui apontada tem como foco no valor desde a fase de ideação, durante o ciclo de desenvolvimento (iterações), e após a entrega final do projeto (incrementos e atualizações). A discussão aqui apresentada visa fomentar pesquisas que tratem uma realidade em que as iterações devem contemplar a participação dos principais stakeholders do projeto e, sobretudo, que o cliente do projeto esteja presente para dar seu olhar sobre a entrega de valor a cada etapa. O cliente neste 
contexto também tem o papel de co-criador de valor.

Nas oportunidades de iteração, e como ações resultantes dela, o valor da entrega feita em cada etapa deve ser mensurado na perspectiva do cliente do projeto, no seu papel de usuário final do produto desenvolvido. Isto deve ser ainda capitalizado pela empresa baseada em projetos, ou equipe da empresa que usa projetos para gestão, como elemento de promoção do projeto, da empresa desenvolvedora do projeto ou equipe de projetos, no relacionamento com stakeholders, ou ainda na valorização da marca da empresa. Os aspectos aqui levantados podem ser suportados pelos pressupostos do Marketing, o que contribui para uma discussão sobre um melhor entendimento dos clientes.

Um exemplo que pode ser apontado é o de uma empresa que inicia o processo de desenvolvimento de um aplicativo para clientes de um banco. $\mathrm{O}$ valor proposto por esse aplicativo deve ser planejado a partir da necessidade do cliente desde o início, que irá, então, guiar a entrega e acompanhamento a cada iteração, levando a eventuais correções de rumo. Esta abordagem é coerente com as diversas ferramentas ágeis alinhadas à processos de ideação, como a co-criação de valor ou o
Design Thinking. Entretanto, infelizmente a percepção de valor a cada iteração não é prática recorrente nos projetos.

Ações de comunicação, poderiam explorar justamente este aspecto, criando valor também para a empresa desenvolvedora do projeto, para ganhos de imagem, ou fortalecimento da equipe. Um projeto mais complexo, de construção de obras de grande porte, por exemplo, pode divulgar em uma campanha de comunicação a qualidade dos materiais e respeito à sociedade e a natureza, como valor percebido por clientes-usuários em uma iteração a respeito da entrega das fundações da obra, e melhorar sua imagem de marca. Esta campanha de comunicação durante as etapas de interação e validação do valor percebido pelo cliente do projeto podem beneficiar ambas as partes antes da entrega final do produto do projeto. $\mathrm{O}$ cliente é beneficiado ao referendar o valor entregue na iteração, e a empresa ou equipe de projetos, se beneficia ao explorar para sua imagem o valor criado.

Os desafios de implementação são grandes, mas os benefícios para o projeto e para a relação com os clientes dos projetos são igualmente relevantes (Ma'arif, Yusnorizam, Hafifi Yusof \& Mohd Satar, 2018). Neste sentido, a função do Product Owner (PO) vem ganhando importância nos 
projetos ágeis, tanto como fator crítico de sucesso (Sverrisdottir, Ingason \& Jonasson, 2014), dada sua interação constante e seu papel de comunicação, entre outros, na gestão de projetos, quanto particularmente na busca por escalar projetos ágeis.

Tanto as pessoas com a visão de negócios quanto gestores de projeto devem compartilhar responsabilidades no contato e interação com os clientes de projeto. Está preocupação com o cliente de projeto está no cerne das funções e papéis das pessoas de negócios (Business Owner), dentre elas priorizar atividades, gerenciar backlogs, gerenciar calendários, arquitetura de projeto, governança do projeto, comunicação, ir aos clientes de projeto, apoio técnico aos clientes, motivação da equipe, negociar conflitos, entre outras funções intimamente relacionada à entrega de valor ao cliente (Remta, Doležel \& Buchalcevová, 2020).

Neste mesma linha, novas iniciativas para a gestão de projetos ganharam impulso ainda com os conceitos de UX (User Experience, ou experiência do usuário), e CX (Customer Experience, ou experiência do consumidor). Estes conceitos são centrados no cliente de projetos. Usualmente a área de projetos estava mais focada no projeto, o que podemos dizer que não basta mais para garantir sucesso do projeto (Ximenes, Alves, Araújo 2015). É preciso repensar o que significa entregar um projeto que satisfaça um cliente. Aspectos relacionados a satisfação estão ligados a incrementos e evoluções que são entregues a cada iteração.

Portanto, cada vez mais as organizações reconhecem que as receitas, e a base de clientes, aumentam quando se considera a experiência do cliente com o projeto (Nasiri \& Sadler, 2018). A reflexão que enseja pensar na experiência do cliente/usuário do projeto apresenta uma alteração significativa na gestão de projetos, tradicionalmente focada no triângulo de ferro. Assim, o olhar passou do projeto para o seu beneficiário. Esta alteração vem requerendo dos gerentes de projeto e demais envolvidos, não apenas uma mudança de foco de trabalho, mas uma mudança de cultura e de habilidades técnicas demandas para conduzir este processo de mudança de perspectiva (Mahmoud-Jouini, Midler \& Silberzahn, 2016).

A participação do cliente do projeto se torna mais ativa e corresponsável no desenvolvimento de projetos com a abordagem que contemplam UX/CX. Elementos que garantem a satisfação do cliente estão agora centrados numa 
percepção de valor que é fundamentalmente uma perspectiva que o outro atribui, ou seja, não é determinada pela empresa, mas a guia nas suas ações. A co-criação de valor e valor na perspectiva do cliente vem se tornando aspectos centrais na condução de projetos desde sua concepção. $\mathrm{O}$ ato de servir vem se tornando parte do modo de pensar o projeto porque é para o cliente que ele existe (Fuentes \& Smyth, 2016). Esta reformulação do pensamento de gestão de projetos vem se desenvolvendo ao longo dos últimos anos como parte da abertura da área de projetos a novas áreas do conhecimento (Cova \& Salle, 2005; Obradović, Kostić \& Mitrović, 2016; Turner, Lecoeuvre, Sankaran \& Er, 2018).

Esta abertura depende ainda do modo de pensar dos envolvidos na gestão de projetos, que durante muitos anos adotou a perspectiva de gestão tradicional de projetos. De outro modo, a perspectiva de valor ao cliente se desenvolveu de maneira separada, se distanciando das práticas convencionais de gestão de projetos. Assim, na perspectiva orientada à gestão de projetos de forma predidtiva era reduzida a aproximação do cliente durante a gestão. A mudança aqui observada traz um novo mindset centrado no cliente onde há uma aproximação cada vez maior do cliente com os envolvidos no projeto. O entendimento dos envolvidos na gestão de projetos é que o cliente é relevante. Por outro lado, conforme salientam Bizarrias, Silva, Penha e Russo (2020), o modo de pensar gestão de projetos ainda privilegia, nos indivíduos, o projeto e não a solução evolucionária para atender as necessidades dos clientes.

Com relação aos pressupostos de Marketing aqui destacados como relevantes para avançar na discussão sobre gestão de projetos, a ação de agregar valor é uma tradição do pensamento de Marketing (Kumar, Jones \& Venkatesan 2011), o que se reflete sobre os benefícios desta perspectiva para as organizações. Cabe aqui destacar, que a essência do Marketing está em construir valor a partir da melhor compreensão do comportamento e das necessidades dos clientes, entregar produtos que atendam tais necessidades, garatindo a satisfação e a fidelização destes clientes (Churchill \& Peter, 2003). Deste modo, o cliente que percebe mais valor naquilo que a ele se apresenta (solução trazida pelo projeto), tende a escolher aquela opção, a ser mais leal àquela organização fornecedora, e a resistir a ofertas de concorrentes. Todos estes aspectos são benéficos para a organização, pois o desafio na área de projetos tem sido refletir sobre a adoção desta perspectiva. 
Um exemplo pode ser percebido na aplicação das práticas do Lean inception (Caroli, 2017). Uma prática que auxilia na gestão de projetos ágeis de maneira ainda mais focada, a perspectiva do cliente e do produto na gestão de projetos. A concepção do MVP (Minimum Viable Product) como forma até de se refletir sobre a continuidade do produto, estabelece a ideia de valor na perspectiva do cliente. Novas funcionalidades serão incorporadas se forem valiosas para o consumidor, a partir da compreensão de quem é este cliente e qual utilidade fará do que se está desenvolvendo já durante a ideação. Isto acontecendo tanto em grandes projetos, onde uma primeira percepção de valor pode ser rapidamente avaliada, quanto em projetos menores, na compreensão das evoluções mais diretas do projeto em desenvolvimento (Caroli, 2017).

Portanto, uma perspectiva incremental de desenvolvimento, em que cada etapa possa ser colocada à prova na percepção de valor, enseja que justamente a ideia de valor não seja colocada de lado em nenhum momento. Em iterações mais frequentes, de cunho evolutivo, o valor na perspectiva do cliente, e sua busca são o foco. Mesmo que uma versão preliminar seja colocada em modo de produção, pois a busca pelo retorno é premente nos projetos, pois todo produto possui um grupo de indivíduos com interesse mais imediatos (Early adopters) em consumir aquela versão inicial, o que gera receita, e principalmente o aprendizado como em testes de mercado.

O término de cada iteração também está relacionado a entrega de valor ao cliente. Questões como "Qual é o melhor momento para disponibilizar o incremento de uma iteração em ambiente de produção do cliente?" e "Como garantir a integridade e a qualidade do incremento de uma iteração?" podem surgir. Atuando como ferramenta estratégica e como respostas para as questões acima, o DevOps (Development and Operations) se torna uma ferramenta estratégica, apoiando os times ágeis com a maior qualidade na produção dos incrementos (Raj \& Sinha, 2020), além de aproximar pessoas, processos e times de acordo com as práticas ágeis adotadas pela organização (HemonHildgen, Rowe \& Monnier-Senicourt, 2020). Além disso, o DevOps ganha importância cada vez mais nos times de desenvolvimento por permitir que os processos, desde a concepção da ideia até a produção do incremento, sejam entregues com o maior valor ao negócio do cliente (Žužek et al., 2020). 
Este editorial abre uma janela de oportunidades para realização de pesquisas que tratem de comportamento do consumidor (clientes em projetos), curva de adotantes, ciclo de vida de produtos, entre outros tópicos do campo do Marketing que são poucos explorados em gestão de projetos. Oportunidades que podem ser evidenciadas nas atividades de Discovery, processos de Ideação, papéis de pessoas de negócios (Product Owner e Business Owner) e etapas de feedback como Cerimônias de revisões e retrospectivas.

\section{Referências}

Banfield, R., Lombardo, C. T., \& Wax, T. (2015). Design sprint: A practical guidebook for building great digital products. " O'Reilly Media, Inc.".

\section{Bizarrias, F. S., Silva, L. F. D., Penha, R.,} \& Russo, R. D. F. S. M. (2020).

Relationship Between Marketing and Project Management Success Through Cognitive Process Lens. IEEE Access, 8, 169810-169821.

https://doi:10.1109/access.2020.3023897

Caroli, P. (2017). Lean Inception: como alinhar pessoas e construir o produto certo. $1^{\mathrm{a}}$ ed.São Paulo: Editora Caroli.

Churcill, G. A., \& Peter, J. P. (2000). Marketing: criando valor para o cliente. São Paulo: Saraiva.

Cova, B., \& Salle, R. (2005). Six key points to merge project marketing into project management. International Journal of Project Management, 23(5
SPEC. ISS.), 354-359.

Fuentes, M., \& Smyth, H. (2016). Value co-creation in a project setting: A service-dominant logic perspective. Proceedings of the 32nd Annual ARCOM Conference, ARCOM 2016, 2(September), 1059-1068.

Hemon-Hildgen, A., Rowe, F., \& Monnier-Senicourt, L. (2020). Orchestrating automation and sharing in DevOps teams: a revelatory case of job satisfaction factors, risk and work conditions. European Journal of Information Systems, 29(5), 474-499. https://doi.org/10.1080/0960085X.2020.17 82276

Kumar, V., Jones, E., Venkatesan, R., \& Leone, R. P. (2011). Is market orientation a source of sustainable competitive advantage or simply the cost of competing? Journal of marketing, 75(1), 16-30. https://doi.org/10.1509/jm.75.1.16

Ma'arif, D., Yusnorizam, M., Hafifi Yusof, M. F., \& Mohd Satar, N. S. (2018). The Challenges of Implementing Agile Scrum in Information System's Project. Journal of Advanves Research in Dynamical \& Control Systems, 10. 58(9), 1803-1817.

Magistretti, S., Dell'Era, C., \& Doppio, N. (2020). Design sprint for SMEs: an organizational taxonomy based on configuration theory. Management Decision.

https://doi.org/10.1108/MD-10-2019-1501

Mahmoud-Jouini, S. B., Midler, C., \& Silberzahn, P. (2016). Contributions of design thinking to project management in an innovation context. Project Management Journal, 47(2), 144156.https://doi.org/10.1002/pmj.21577 
Nasiri, A., \& Sadler, H. (2018). UXUPUser eXperience centric unified process. In 2018 IEEE International Conference on Engineering, Technology and Innovation (ICE/ITMC) (pp. 1-9). IEEE.https://10.1109/ICE.2018.8436376

Obradović, V., Kostić, S. C., \& Mitrović, Z. (2016). Rethinking Project Management - Did We Miss Marketing Management? Procedia - Social and Behavioral Sciences, 226(October 2015), 390-397. https://doi.org/10.1016/j.sbspro.2016.06. 203

Raj, P., \& Sinha, P. (2015). Project Management In Era Of Agile And Devops Methodlogies. International Journal Of Scientific \& Technology Research, 9(1), 1024-1033.

Remta, D., Doležel, M., \& Buchalcevová, A. (2020, June). Exploring the product owner role within safe implementation in a multinational enterprise. In International Conference on Agile Software Development (pp. 92-100). Springer, Cham.

https://doi.org/10.1007/978-3-030-588588_10

Sverrisdottir, H. S., Ingason, H. T., \& Jonasson, H. I. (2014). The role of the product owner in scrum-comparison between theory and practices. ProcediaSocial and Behavioral Sciences, 119, 257-267.

Turner, J. R., Lecoeuvre, L., Sankaran, S., \& Er, M. (2018). Marketing for the project: project marketing by the contractor. International Journal of Managing Projects in Business. https://doi.org/10.1108/IJMPB-10-2017-
0118

Ximenes B.H., Alves I.N., Araújo C.C. (2015) Software Project Management Combining Agile, Lean Startup and Design Thinking. In: Marcus A. (eds) Design, User Experience, and Usability: Design Discourse. Lecture Notes in Computer Science, vol 9186. Springer, Cham. https://doi.org/10.1007/978-3319-20886-2_34

Žužek, T., Kušar, J., Rihar, L., \& Berlec, T. (2020). Agile-Concurrent hybrid: A framework for concurrent product development using Scrum. Concurrent Engineering, 28(4), 255-264. https://doi.org/10.1177/1063293X20958 541 